\title{
THE JOINT HURRICANE TEST BED \\ Its First Decade of Tropical Cyclone Research-To-Operations Activities Reviewed
}

\author{
by Edward N. Rappaport, Jiann-Gwo Jing, Christopher W. Landsea, \\ Shirley T. Murillo, and James L. Franklin
}

\begin{abstract}
Collaboration between researchers, forecasters and technology specialists facilitated the development and implementation of numerous projects benefitting forecast operations.
\end{abstract}

$\mathrm{T}$ he National Oceanic and Atmospheric Administration (NOAA), in conjunction with the U.S. Weather Research Program (USWRP), established the Joint Hurricane Test Bed (also popularly, "Testbed") (JHT) in 2001 to expedite the transfer of tropical cyclone research into forecast operations (Rappaport et al. 2009; Knabb et al. 2005). The JHT's first decade coincided with several significant advances at the National Hurricane Center (NHC; see Rappaport et al. 2009; Franklin 2010): NHC extended its forecast horizon from 3 to 5 days and its track forecast errors decreased significantly, in large part due to improvements in operational computer model

AFFILIATIONS: RAPPAPORT, JIING, LANDSEA, AND FRANKLINNational Weather Service, National Centers for Environmental Prediction, National Hurricane Center, Miami, Florida; MurilloOffice of Oceanic and Atmospheric Research, Atlantic Oceanographic and Meteorological Laboratory, Hurricane Research Division, Miami, Florida CORRESPONDING AUTHOR: Edward N. Rappaport, National Hurricane Center, II69I SW 17th Street, Miami, FL 33165-2149 E-mail: edward.n.rappaport@noaa.gov

The abstract for this article can be found in this issue, following the table of contents.

DOI:10.1175/BAMS-D-II-00037.I

In final form II October 2011 forecast guidance and tools available to forecasters. During that period the JHT funded 62 projects, with operational offices implementing most of them.

In this review of the JHT, we look at the program's contribution to the forecast process. We present the JHT's primary objectives and processes, along with key characteristics of the resulting applied research projects it supported. The evaluation describes the operational impact of the program as indicated by the JHT's primary customer, NHC's "hurricane specialists" (forecasters); considers the effect of JHT projects on conventional forecast metrics; and highlights a few nontraditional measures of the test bed's contribution. Along the way, we introduce the projects that have had the greatest impact as a way to give a sense of the kind of successfully applied research that the JHT has sponsored. We also identify some of the program's limitations and discuss prospects for the test bed.

\section{PROGRAM OBJECTIVES AND PRACTICES.}

Two JHT documents and the test bed's annual budget define the focus and scope of JHT activities, including the type and number of funded projects. The NOAA/ NHC terms of reference (TOR; NOAA/NHC 2002) provide the test bed's mission "to transfer more rapidly and smoothly new technology, research results, and observational advances of the USWRP, its sponsoring agencies, the academic community and other groups 
into improved tropical cyclone analysis and prediction at operational centers." The JHT's three-member administrative staff, a steering committee (SC), and NHC and other NOAA staff applied the TOR to help guide the JHT through each project's selection, testing, and potential implementation process.

The JHT operates on a 2 -yr cycle, initiated by a federal register notice announcement of opportunity (AO). The AO lists the areas of operational need as prioritized mainly by NHC hurricane specialists and the NOAA/National Centers for Environmental Prediction (NCEP)/Environmental Modeling Center (EMC). The most recent list, used for the JHT's sixth proposal process, can be seen at the NHC's online library of JHT information (e.g., NOAA/OAR 2010). It shows guidance on intensity forecasting as the top priority of the three offices covered by the JHT: NHC, Central Pacific Hurricane Center, and Joint Typhoon Warning Center. Among the other highest stated needs are advanced observational capabilities, guidance for extended period forecasts, increased efficiency in the forecast process, and several forecast model-related deficiencies.

The JHT employs a two-step review process. Each candidate submits a brief letter of intent for review. The AO provides criteria applied by the SC to both the letters of intent and to the subsequent subset of full proposals. The key factors are the project's relevance/ connection to operational priorities, technical merit, research maturity, qualification of applicant, and project cost.

Types of projects. The JHT annual budget for projects has been \$1-1.5 million. Recognizing that level of resources, the $\mathrm{AO}$ indicates that the grants are usually for $\$ 50,000-\$ 200,000$ per year for each of about $10-15$ projects per cycle. Details about the 62 funded projects from the JHT's first five rounds are provided online (www.nhc.noaa.gov/jht/past_projects.php).

The projects for the first five rounds were distributed by topic area, as shown in Fig. 1. (Five projects had multiple components and were counted as contributing to more than one area in the figure.) In total, the projects designed to improve operational numerical model guidance on tropical cyclones and the applications that used the output from those models comprised more than two-thirds of the projects. The JHT supported both dynamically and statistically based model upgrade work. Most of the dynamic model work occurred on NOAA's Geophysical Fluid Dynamics Laboratory (GFDL) (Bender et al. 2007) and Hurricane Weather Research and Forecast (HWRF; Surgi et al. 2010) models. Other projects in this category sought to make improvements that were not specific to a particular atmospheric model, for example, seeking improvements to parameterizations in ocean models coupled to an atmospheric simulation.

Work on statistical models was directed at improving forecasts of tropical cyclone intensity, defined as the maximum 1-min-averaged wind speed at 10-m altitude. This work occurred mainly with the Statistical Hurricane Intensity Prediction Scheme (SHIPS). Special emphasis was placed on "rapid intensification" ("RI") when the intensity increases by at least $30 \mathrm{kt}$ in $24 \mathrm{~h}$.

About one-quarter of the projects were directed at either improving observing systems or analyzing the observations. Most of those, such as improving the utility of the Stepped-Frequency Microwave Radiometer, were intended to help the forecasters to better analyze storm structure, mainly the surface wind speed. Others, like airborne targeting techniques, were intended to improve the initialization of the dynamical models.

\section{ASSESSMENT OF OPERATIONAL IMPACT.} We focus on the JHT's contributions to the NHC's forecast operations rather than, for example, the downstream impact on a particular sector of the user community. We begin with the views of NHC's hurricane forecasters. 
Forecaster perspective. The authors invited NHC's hurricane specialists to rate the completed JHT projects. The forecasters gave a score of 0 when, in their view, a project did not have a net positive impact, 1 for a minor benefit to forecast operations, and 2 for a significant operational advance. We recall that the charge given to the JHT-to facilitate the transfer of promising research to operations within a period of about two years with modest funding-constrains the scope of JHT's activities. In that context, a rating of 2 represents a fully successful project. Because a project could exceed the goals of the program, the forecasters could rate a project as high as " 3 " to indicate a resulting transformational advance. The forecasters also used this system to score the JHT as a program, but they were not constrained to whole numbers. Results came from a variable, nonhomogeneous group of forecasters and were based on their subjective assessments. Nevertheless, as the primary customers of the JHT, the forecasters provide an important perspective to consider.

For this review, "operational" means that NCEP managers decided to accept a completed JHT project into regular operational use, and the steps of technical implementation were completed at those centers. Most projects implemented operationally at the NHC are real-time applications, whereas at the EMC they are enhancements to operational numerical weather prediction (NWP) models, whose output is used as guidance by NHC forecasters. For projects with multiple components, the forecasters were asked to indicate the highest rating for any of the component accomplishments.

Twelve current and former NHC hurricane specialists participated in the survey. They gave an average score of 2.2 to the JHT program. Translated, this indicates that the program is a positive contribution, between significant and transformational (though closer to the former).

Figure 2 shows the distribution of scores for the projects of the JHT's first four rounds. The average score for the implemented projects was 1.3, a solid rating in the applied scoring system. This level of performance has remained steady, varying from 1.2 to 1.4 for each of the first four rounds. Three projects each scored 2 , on average, corresponding to a significant operational advance. One project scored even higher (2.2), which is indicative of a breakthrough contribution. We discuss this project briefly later.

Considered by topic area, the scores for the dynamical modeling and postprocessed applications were bimodal; some in each category were not approved for operations, but those that were implemented got relatively high marks. The statistical model project scores were rather evenly spread. Projects related to observations and/or analyses contributed less, on average, according to the forecasters.

Model guidance and official product accuracy. The JHT can also be evaluated for the changes it induced in forecast accuracy. Several issues, however, complicate the effort to quantify the JHT's contribution, or at least make it difficult to interpret the results unambiguously. For example, the NHC issues the forecasts seen by most people. The JHT, however, seeks to improve forecasts mainly through advancing the accuracy of the models that provide guidance to forecasters. This makes the influence of JHT projects on the public forecast indirect. Also, because NHC forecasters have multiple models at their disposal, and because the process a meteorologist uses to develop a forecast is unique to the individual, complex, and not readily quantifiable, it is not possible to isolate the impact of an individual JHT project on the "official" forecast unless a model provided a fundamental breakthrough, accounting for, say, a $20 \%$ improvement in forecast accuracy. Perhaps not surprisingly, given the JHT's objectives, framework, and resources, no such profound advance has occurred. We discuss further this limitation at the end of the paper.

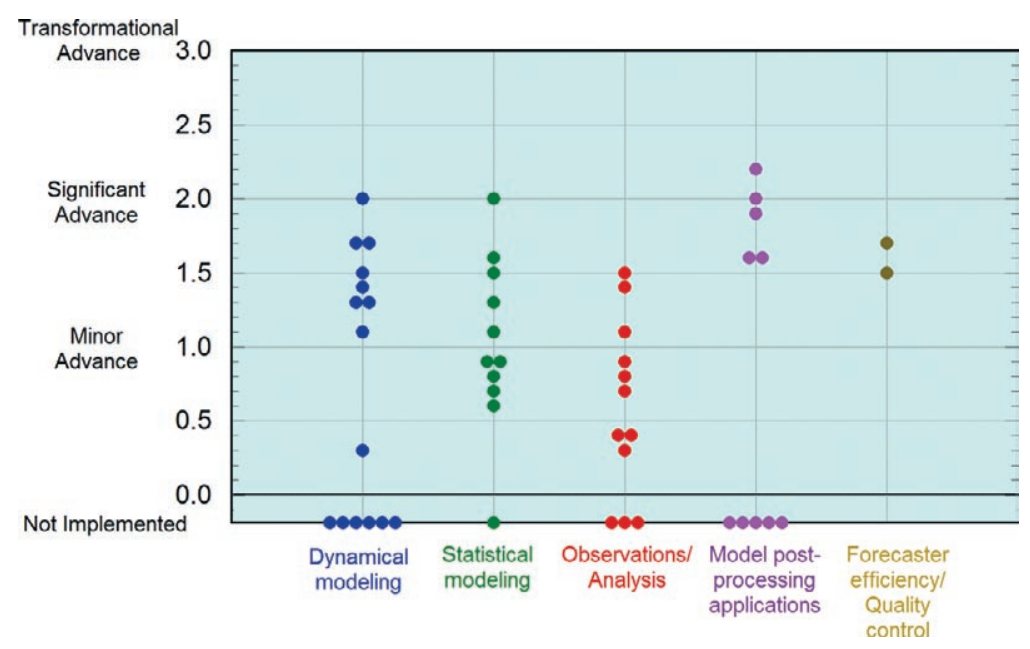

FIG. 2. Averaged forecaster ratings by topic area for the $\mathbf{5 0}$ projects from the JHT's first four rounds, with tallies of projects not implemented shown along the base of figure. 
With the above considerations in mind, we begin by looking at the impact of the JHT on model forecasts. The conventional measures of forecast performance are the accuracy of track (center position) and intensity (maximum wind speed) predictions.

TRACK FORECASTS. Figure 3 indicates that the annual average track errors of NHC's mainstay models decreased soon after the JHT's first projects concluded in 2001-02. The largest decrease occurred with the GFDL model. That model had among the largest 48-h track forecast errors in 2001 and 2002, but starting in 2003 it had smaller track errors than the other models for three consecutive years at the important 2-day forecast period. Elsberry (2005) noted that upgrades to the operational GFDL model in 2003 came in part from work on that model sponsored by the JHT in 2001-02 ("Hurricane transition to operations at NCEP/EMC”; N. Surgi, project lead). We speculate that some of the large improvement in the GFDL model during this period can be attributed to JHTsupported work on that model. Three (of the then six) NHC forecasters provided ratings for this GFDL project, each rating it a 2 , indicating a significant positive contribution in their view, tying it for the second-highest average score for a project.

Elsberry further suggested that the JHT's test and evaluation process, which involves the forecasters and provides them advance familiarity with the model's performance and characteristics, expedited the fore-

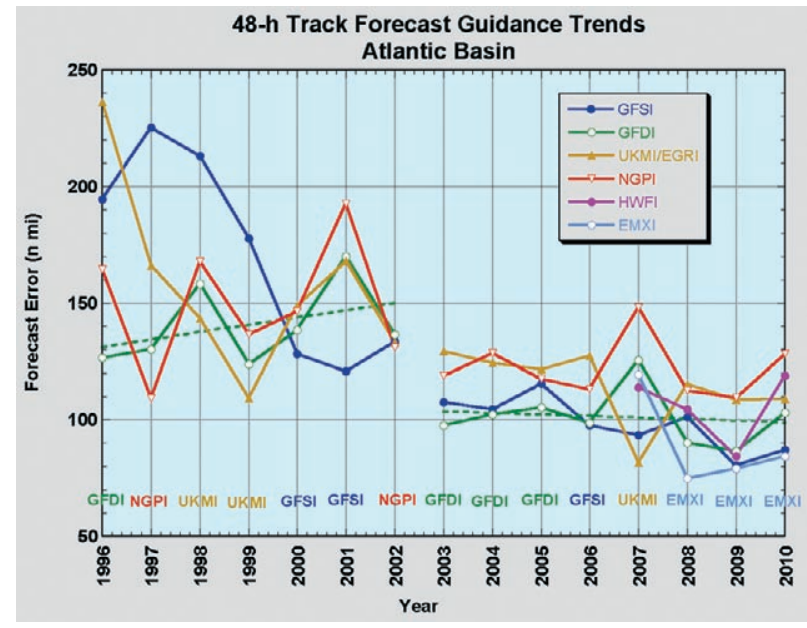

Fig. 3. Annual average Atlantic 48-h track forecast error for NHC's primary model guidance. GFDI represents the interpolated version of the GFDL model (see www.nhc.noaa.gov/verification for details.) Trends for GFDI for 1996-2002 and 2003-10 are shown (dashed lines). The top performing model for each hurricane season is indicated just above the associated year. casters' application of the model when the upgraded version of it became available to them operationally in 2003. The same could be said about some of the JHT's other applications.

The trend lines superimposed on Fig. 3 show that after the downward step at 2003, the rate of improvement for the GFDL model has been small. This could be an indication that, after several decades of significant improvements in track forecasting, it is becoming increasingly difficult to make comparable gains through that approach as we near some limit of predictability. It is also likely a reflection of NOAA turning its attention from the GFDL model to the HWRF model. No proposals to improve the GFDL model were submitted after the third round (2005-07).

Forecasters know that the "consensus" tropical cyclone forecast track, found by combining predictions from the normally best-performing individual NWP models, has provided the most accurate guidance, on average, in most years. The project "Quantifying tropical cyclone track forecast uncertainty and improving extended-range tropical cyclone track forecasts using an ensemble of dynamical models" (J. S. Goerss, project lead, 2003-05) received (in a tie) the forecasters' second-highest score of 2.0. This project introduced a new consensus scheme known as CONU. ${ }^{1}$ CONU provided a track from the average forecast locations of the primary operational models when at least two of those models were available. It supplanted the previous operational consensus scheme, which required the presence of all four of its component models, as the forecasters' choice because of CONU's comparable performance quality and superior availability. For 120 -h forecasts during the test period, for example, the previous scheme and CONU were available to the forecasters $50 \%$ and $85 \%$ of the time, respectively.

Turning to NHC track forecasts, Fig. 4 (top) hints at a slight downward step in errors in 2003, corresponding to the drop seen in Fig. 3. Trend lines, however, show little if any change in the rate of improvement from the pre-JHT to the JHT periods. Figure 4 (bottom) provides a more positive take on the JHT impact. It shows the annually averaged errors in skill space, where natural year-to-year forecast difficulty, as represented in the benchmark Climatology

\footnotetext{
${ }^{1}$ This consensus model is now referred to as Track Variable Consensus Atlantic (TVCA) and Track Variable Consensus Eastern North Pacific (TVCE) for the Atlantic and eastern North Pacific basins, respectively.
} 
and Persistence (CLIPER) model (Aberson 1998), is removed. Trend lines suggest an increased rate of improvement in skill during the JHT era (i.e., the continued decrease in forecast error to which the JHT contributed came during an era of increased forecast difficulty).

We noted above some of the factors that make it difficult to interpret these verification analyses. There are others. For example, concomitant system upgrades, some of which were developed outside the JHT framework - such as improvements to the resolution and data assimilation of global models-obscure JHT impacts. Further, some of the work completed by JHT-funded scientists might have been done even if the JHT was not in place. Viewed broadly, one axiom is that the JHT has become a primary mechanism by which modest to sometimes moderate improvements in the forecast models now occur.

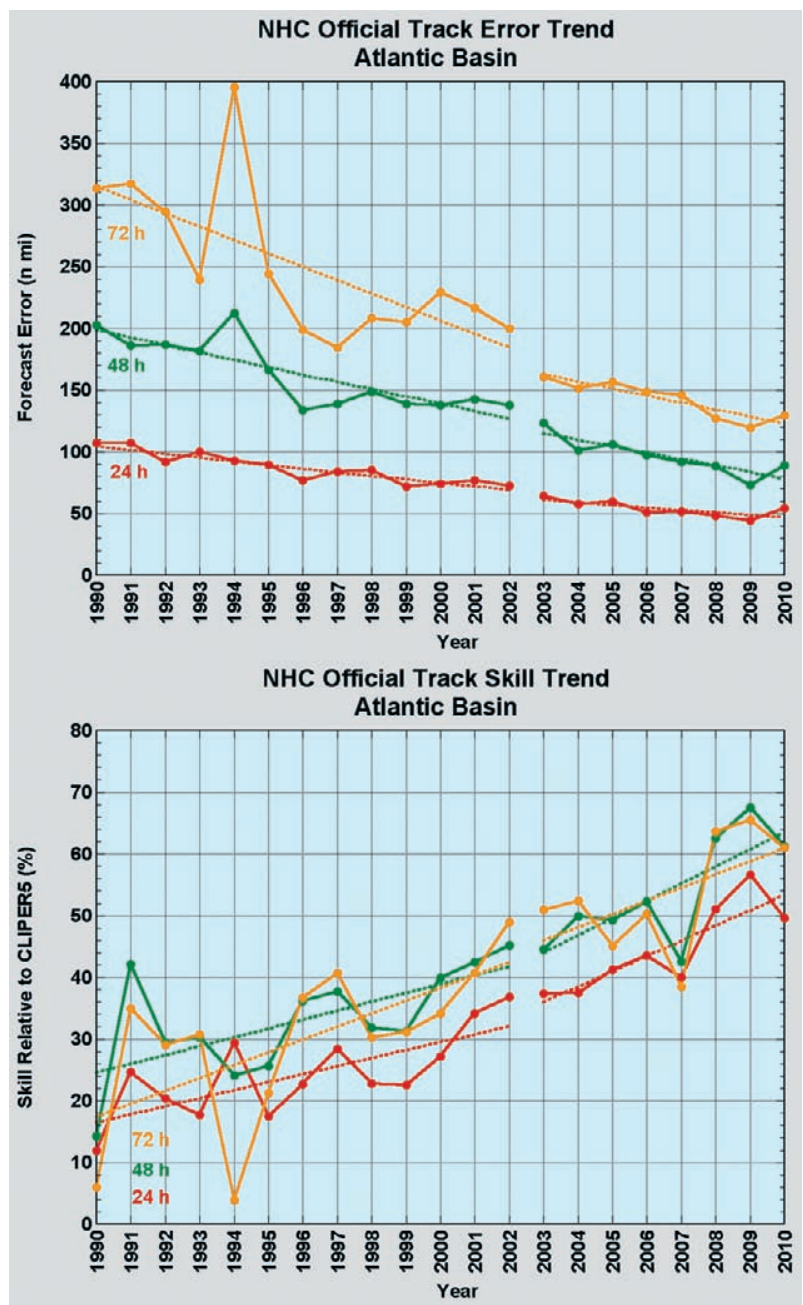

FIG. 4. NHC annual average Atlantic track forecast errors and track forecast skill, with dotted trend lines through 2002 and beginning in 2003.
INTENSITY FORECASTS. Little change in the annual average errors for intensity forecasts had occurred in the years preceding establishment of the JHT. That realization led the NHC to put improvements in intensity forecasting in the top spot on its list of JHT priorities.

JHT efforts in this area have yet to provide significant improvements in the annual averages of the official intensity forecast errors (Fig. 5, top). As was noted for track forecasts, however, the JHT has operated during a period of more-difficult-than-normal intensity forecasts. Viewed from the perspective of intensity forecast skill (Fig. 5, bottom), with the version of the Statistical Hurricane Intensity Forecast model that accounts for storm decay over land (DeMaria et al. 2006, Knaff et al. 2003) serving as the baseline of rather noisy data, some gains appear to have been made during the JHT era.
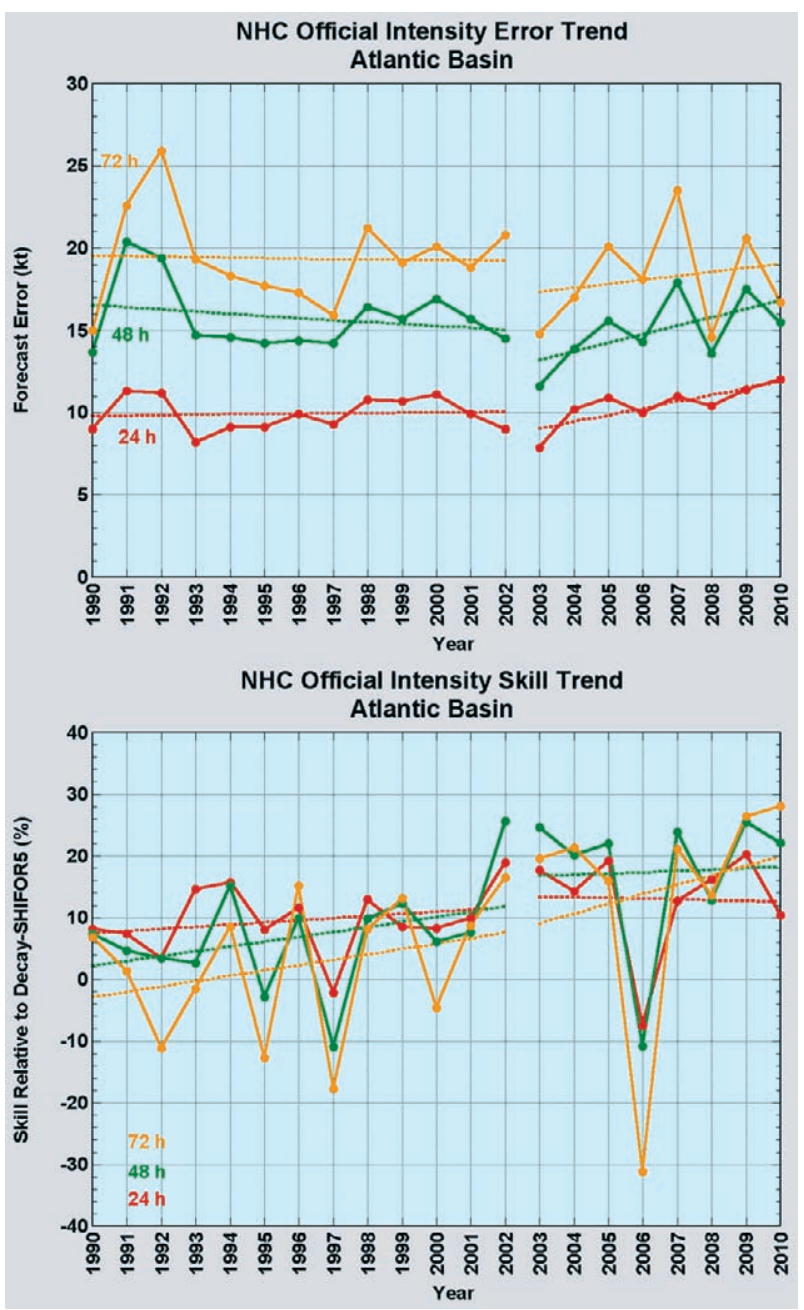

Fıg. 5. NHC annual average Atlantic intensity forecast errors and intensity forecast skill, with trend lines through 2002 and beginning in 2003. 


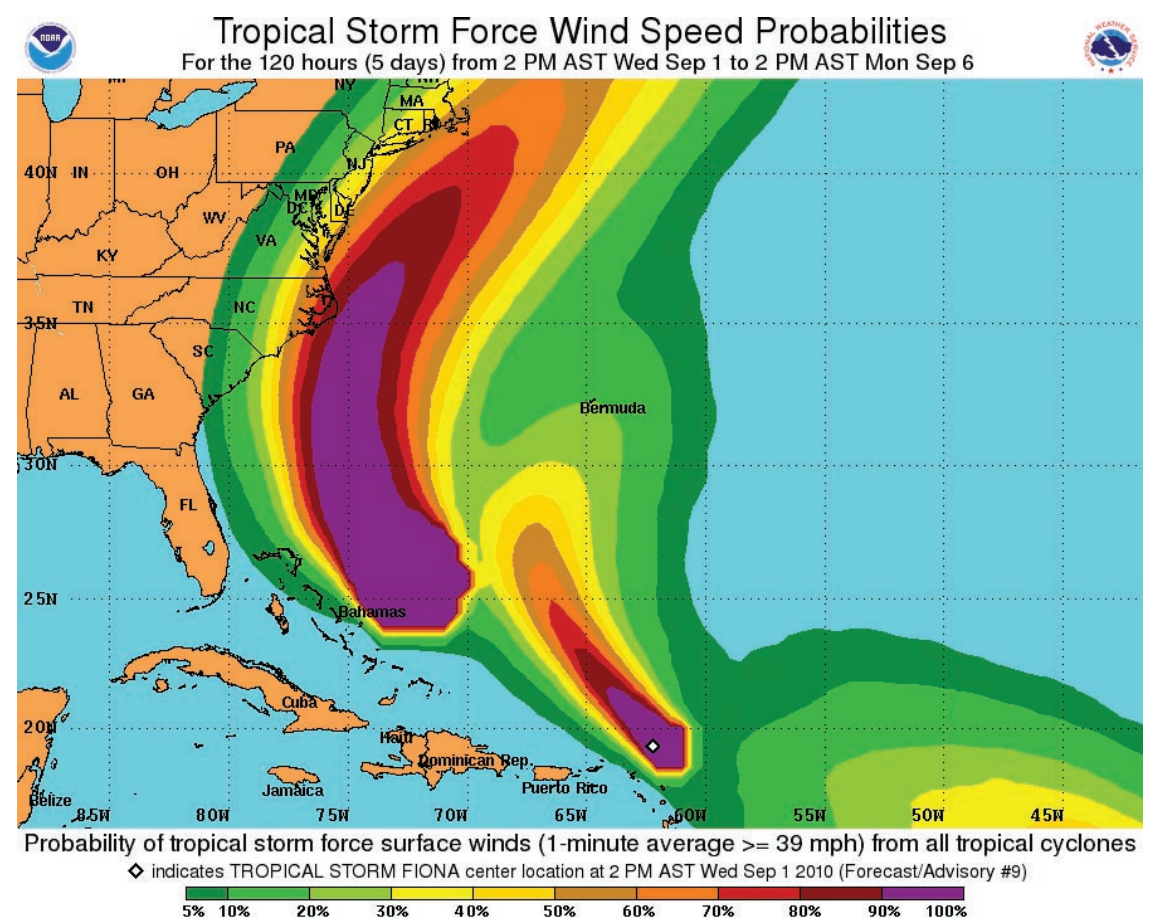

FIG. 6. Wind speed probabilities for I-min tropical storm force winds (at least $39 \mathrm{mph} / 63 \mathrm{kph}$ ) issued by NHC at 2100 UTC I Sep 2010 for the combined forecasts of Hurricane Earl (centered initially just east of the Bahamas), Tropical Storm Fiona (centered initially northeast of Puerto Rico), and Tropical Storm Gaston (centered initially off the edge of the figure between Africa and the Caribbean).

The advance in skill came from upgrades in the statistically based models. As an example, the "Improved statistical intensity forecast models" project (J. A. Knaff et al., project investigators, 2005-07) tied for second place in the forecaster's ranking with a score of 2.0. It made two important improvements to SHIPS. SHIPS, and its successor Decay Statistical Hurricane Intensity Prediction Scheme (DSHIPS), which accounts for decay over land, have provided the most accurate intensity guidance on average. A $2 \%-8 \%$ improvement in DSHIPS at all forecast lead times for storms near land resulted from this project's method of accounting for the impact of small islands encountered by storms (DeMaria et al. 2006). A similar positive impact on DSHIPS was obtained from the improved way the scheme handled wind shear, and from using a new vortex variable.

A statistical technique that provides RI guidance was also improved by a JHT project, as described by Kaplan et al. (2010).

The JHT has also led indirectly to advances in forecast methods. JHT investigators working on the DSHIPS project mentioned just above identified a limitation of SHIPS that they later addressed by developing the Logistic Growth Equation Model
(LGEM) outside of the JHT framework. LGEM leveraged the databases that were assembled under JHT support and made use of some of the components of the SHIPS model that were improved with JHT funding, such as a vortex removal technique and an inland decay component. LGEM now is typically the most accurate intensity forecast model, especially at longer forecast periods (Cangialosi and Franklin 2011).

The JHT has supported development of HWRF, NOAA's newest and first nonhydrostatic operational regional hurricane forecast model. This model provides a framework for improvements in forecast guidance on intensity.

Other advances. Some of the JHT's most important contributions occurred outside the conventional framework of track and intensity forecast accuracy. In this section we briefly discuss three of those advances that are valued highly by forecasters.

NeW PUbLIC PRODUCTS. The project receiving the highest score from the forecasters was not one intended to provide them with more accurate guidance or to otherwise help them make more accurate forecasts. Rather, the most important component of "Improvements in deterministic and probabilistic tropical cyclone surface wind predictions" (J. A. Knaff and M. DeMaria, project investigators, 2003-05; score: 2.2) generated probabilistic information for "end users" on the geographical distribution of the threat of high winds based on NHC's official forecast (DeMaria et al. 2009). From this work the first (and so far only) new NHC public product developed with support from the JHT was derived. Figure 6 shows an example of the graphical wind speed probability product covering the 5-day forecast period. From this project, NHC now issues a companion text product (e.g., www.nhc.noaa .gov/archive/201I/ARLENE.shtml?) that provides the probabilities of occurrence of three wind speed 
thresholds over the following five days at numerous locations.

GUIDANCE ON GUIDANCE. A second part of the work by Goerss described above was one of the JHT activities designed to give forecasters better "guidance on guidance," that is, techniques that provide information to the forecasters about the likely performance of the models during the forecast situation at hand, rather than an improvement of a model. This part of the study found that the CONU track error was a strong function of the spread of the component models and of the initial and forecast intensity (Goerss 2007). From the forecast error distributions, the researcher developed the Goerss prediction of consensus error (GPCE) "confidence circles" centered on the CONU forecast point that would be expected to contain the actual position at the forecast time about $75 \%$ of the time (Fig. 7). These displays help the forecaster know and convey the forecast uncertainty.

A follow-on effort to the top-rated project by DeMaria et al. (2009) discussed above was another prized application in the guidance on guidance genre. It helped develop outreach materials used by the NHC for training forecasters at NWS Weather Forecast Offices and others on how to interpret and use the wind speed probability products, including how the probabilities could be used by the NWS in its decision process for issuing tropical storm and hurricane warnings and watches.

FORECAST PROCESS EFFICIENCY. The NHC forecasters put a high priority on potential improvements to their operating environment. The less time they spend on the mechanics of generating the forecast, the more time they will have for considering and documenting the science and service issues for that forecast cycle.

A key part of their local information technology infrastructure for the past twenty years has been the Automated Tropical Cy- clone Forecast System (ATCF; see Miller et al. 1990; Rappaport et al.2009). About 50 upgrades to the ATCF system environment came from the "Development and implementation of NHC/JHT products in ATCF" project (C. R. Sampson, project investigator, 2005-07). The operational display of the confidence circles shown in Fig. 7 was one of them. Other examples included expanding model display capabilities; other new visualization options; a different logging process for "special" advisory information to facilitate forecast verification; and technical improvements to handle error checking, changes to the operating system, software bug fixes, etc.

WHAT HELPED AND WHAT DID NOT. We have indicated which types of projects were most successful and least successful (e.g., Fig. 2) and, in the case of the former, provided a few examples thereof. To offer insight into future test beds, we now introduce a few key programmatic considerations beyond the JHT's particularly effective TOR, which has required no significant change, and the participation by the forecasters from start (establishing priorities) to finish (providing input to the implementation decision).

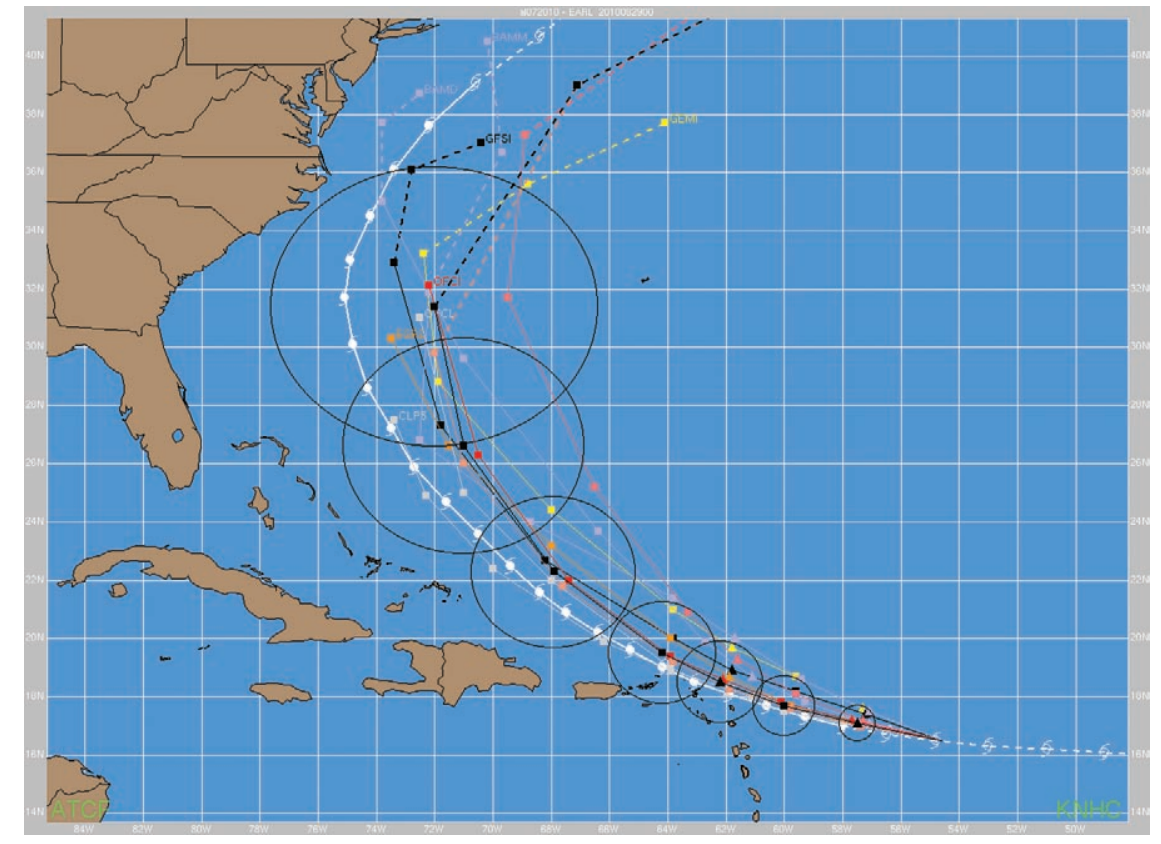

FIG. 7. Example of GPCE (black circles) providing $75 \%$ confidence guidance to forecasters for the Hurricane Earl track forecast from 0000 UTC 29 Aug 2010 , when Earl's center was located near the tropical storm symbol at $\sim 16^{\circ} \mathrm{N}$, $55^{\circ} \mathrm{W}$. Lines emanating from there are model and NHC forecasts. Symbols along the white line provide the subsequent 6-hourly center locations and intensity information for Earl determined by NHC forecasters from their poststorm analyses. 
Test beds are intended to bridge the work and work environments of researchers and operational personnel. For the JHT, these material and cultural differences include information technology (e.g., computer capabilities, security, and communication and software protocols), test standards, product reliability and timeliness, expectations about the processes to be employed, and documentation requirements. The JHT has been successful because of the willingness of researchers, as well as operational staff, to work closely to develop and employ collaborative procedures. The SC, for example, assesses and provides extensive comments on all letters of intent, proposals, and first-year reports submitted to the JHT. SC members must forego certain opportunities available to their colleagues because the JHT employs a "recusal" process prohibiting them from being funded as a JHT investigator or from participating in reviews or voting on proposals for funding for their local organization. Members of the SC represent the field of tropical meteorology, which is not large, and, as volunteers, their contributions and sacrifices were particularly appreciated.

Completing the JHT's 1- or 2-yr development, testing, and evaluation process does not assure a project's positive impact on forecast operations. After the conclusion of a project's test and evaluation period, the operational offices weigh the projected benefits and costs of each project. The NCEP director, as part of NCEP's model implementation process that includes input from operational offices, then decides which potential model upgrades are to be accepted to run on NCEP's central operations mainframe computing facilities. For the remaining projects and the forecaster applications, the NHC director decides which should enter the local implementation process based on four criteria that are similar to those applied in the proposal review process:

- Forecast or analysis benefit: expected improvement in operational forecast and/or analysis;

- Efficiency: adherence to forecaster time constraints and ease-of-use needs;

- Compatibility: information technology compatibility with operational hardware, software, data, communications, etc.;

- Sustainability: availability of resources to operate, upgrade, and/or provide support.

To make the decision, the NHC director considers input from the researcher's final JHT report, the JHT administrative staff, forecasters serving as project "focal points," and NHC information technology experts. Falling short in any of the standards can be reason for either postponing implementation pending additional work or scrapping the project. In the case of the first bulleted item, for example, what was projected to be a benefit during the proposal stage might not have shown a sufficient positive impact to be acceptable when subjected to the independent data used during the test period. Of the 50 projects funded in the first five rounds, 15 (30\%) were declined for operational implementation.

The JHT had programmatic difficulties as well as successes. A total of 15 test bed researchers, forecasters, and members of the SC and JHT administration identified their concerns. Among them, the JHT staff and SC spend much time ensuring that the program complies with administrative and legal guidance about government proposal and funding activities. The funding process for grants is complex and protracted, taking about 15 months to complete.

The test bed's policy that allows subunits of NOAA to compete against external applicants for resources represented one area of concern. However, many organizations were part of the process, as shown for the funding in aggregate in Fig. 8. To date, the funded organizations include 13 academic institutions, 5 private sector firms, and 13 federal offices. This diversity can be counted as one of the JHT's successes.

The money provided per project averaged around $\$ 100,000$ per year. No project has received more than about $\$ 200,000$ per year. These levels are lower than those available through other options [e.g., National Science Foundation], which may explain why the number of letters of intent to the JHT in each of its six cycles has never exceeded about 40 . The relatively low funding levels can be also explained in part by noting that, to date, only NOAA has contributed to the funds for projects, though the original JHT plan was to have at least two additional non-NOAA funding partners, that is, an intended "Joint" part of JHT.

PROSPECTS FOR THE JHT. Decisions on the possible operational implementation of the JHT's fifth round of projects (www.nhc.noaa.gov/jht/09-II_proj .shtml) will occur in early 2012. The JHT has also begun its sixth 2 -yr cycle. It received more than 30 letters of intent, which later narrowed to 23 qualifying full proposals, from which 12 have been selected for funding. These numbers, which are comparable to previous rounds, suggest that the test bed retains steady, if not full, interest within the tropical meteorology community.

The program's 2-yr maximum period, the limited budgets for test bed projects, and the information 


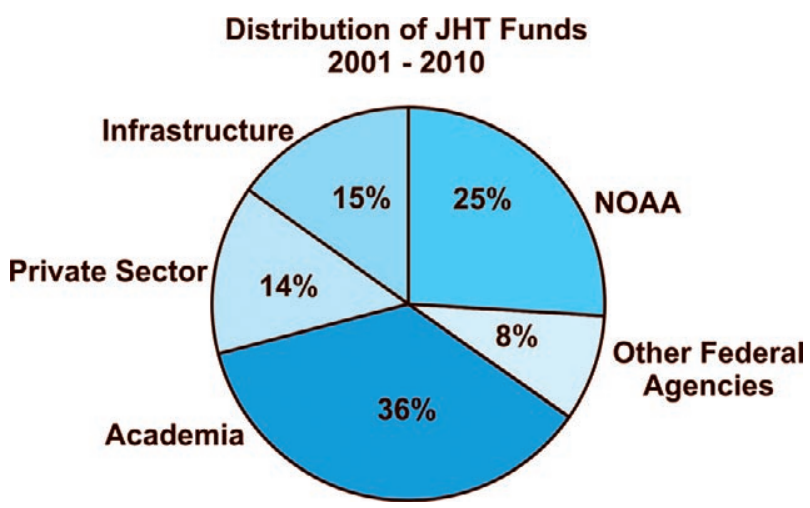

FIG. 8. Distribution of JHT funds, 200I-I0.

technology needs of the receiving operational offices, however, impose constraints on the types of proposals the JHT selected. For example, the dynamical modelrelated proposals selected by the JHT were focused on either existing or already-planned operational forecast models and computing systems. It is understandable how, given that environment, the JHT specialized in facilitating the transfer from research to operations of enhancements that could best be characterized as incremental (though in some cases significant), rather than transformational.

Additional forecast improvements are necessary. More substantial developmental activities than the JHT has supported to date, such as advanced observing systems and new models or major upgrades to existing models requiring greater computing capabilities, are likely necessary to overcome some of the bigger challenges facing the operational tropical cyclone program. From the experiences to date, it appears that resources far exceeding those available to date for the JHT are required.

NOAA established the Hurricane Forecast Improvement Project (HFIP) in 2008-09 to address these larger and more expensive tasks. HFIP is a 10 -yr project designed to accelerate improvements in 1- to 7-day forecasts for hurricane track, intensity, and storm surge, and to reduce forecast uncertainty. HFIP has very ambitious goals for model guidance (see www.hfip.org), including a 50\% reduction in forecast error within a decade. HFIP's budget, about an order of magnitude larger than the JHT's, is more commensurate with those goals than the JHT's. HFIP includes a focus on advancing the HWRF model, whose initial development was supported by the JHT. Early results, for example, using wind data from airborne Doppler radar to initialize mesoscale models, appear promising (Zhang et al. 2011).

The JHT can remain an important program and become even more effective by complementing HFIP.
The JHT can continue to facilitate the transfer of non-HFIP-funded research to operations. It can also serve as a mechanism to improve operations using spinoff work coming from HFIP.

The future of the JHT will depend on the availability of funds during an era of expected austere federal budgets. To date, NOAA has provided an average of about $\$ 1.3$ million per year to the JHT. Compared to the annual $\sim \$ 10$ billion in damage (Pielke et al. 2008) and large loss of life associated with tropical cyclones in the United States alone, the JHT budget, which is intended to expedite improvements in hurricane forecasts, seems modest given the significant successes realized by the test bed during its first decade.

ACKNOWLEDGMENTS. The NHC hurricane specialists and other JHT contributors provided input that greatly facilitated this review of the test bed. The following sectors and institutions of the meteorological community have contributed to the JHT through work on test bed projects: Cooperative Institute for Mesoscale Meteorological Studies, Cooperative Institute for Research in the Atmosphere, NASA Goddard Space Flight Center, Naval Research Laboratory, NOAA/NESDIS/Office of Research and Applications, NOAA/NWS/Environmental Modeling Center, NOAA/NWS/Hydrometeorological Prediction Center, NOAA/NWS/National Hurricane Center, NOAA/OAR/Earth System Research Laboratory, NOAA/OAR/Geophysical Fluid Dynamics Laboratory, NOAA/OAR/Atlantic Oceanographic and Meteorological Laboratory, NOAA/OMAO/Aircraft Operations Center, U.S. Air Force Reserves, Naval Postgraduate School, Old Dominion University, UCAR/NCAR Earth Observing Laboratory, UCAR/NCAR Visiting Scientist Program, U.S. Air Force Academy, University of Alabama, University of Central Florida, University of Hawaii, University of Maryland, University of Miami, University of Rhode Island, University of Western Ontario, University of Wisconsin, and Computer Science Corporation, ProSensing, Inc., Remote Sensing Solutions, Inc., Remote Sensing Systems, and Science Applications International Corporation. The authors thank BAMS Editorial Board Chair Jeff Waldstreicher and the reviewers for comments that improved the manuscript.

\section{REFERENCES}

Aberson, S. D., 1998: Five-day tropical cyclone track forecasts in the North Atlantic basin. Wea. Forecasting, 13, 1005-1015.

Bender, M. A., I. Ginis, R. Tuleya, B. Thomas, and T. Marchok, 2007: The operational GFDL coupled 
hurricane-ocean prediction system and a summary of its performance. Mon. Wea. Rev., 135, 3965-3989.

Cangialosi, J. P., and J. L. Franklin, 2011: 2010 National Hurricane Center forecast verification report. NOAA/NWS/NCEP/National Hurricane Center, 77 pp. [Available online at www.nhc.noaa.gov /verification/pdfs/Verification_2010.pdf.]

DeMaria, M., J. A. Knaff, and J. Kaplan, 2006: On the decay of tropical cyclone winds crossing narrow landmasses. J. Appl. Meteor. Climatol., 45, 491-499.

,,-- R. Knabb, C. Lauer, C. R. Sampson, and R. T. DeMaria, 2009: A new method for estimating tropical cyclone wind speed probabilities. Wea. Forecasting, 24, 1573-1591.

Elsberry, R. E., 2005: Achievement of USWRP hurricane landfall research goal. Bull. Amer. Meteor. Soc., 86, 643-645.

Franklin, J. F., cited, 2010: National Hurricane Center forecast verification report. [Available on line at www.nhc.noaa.gov/verification.]

Goerss, J. S., 2007: Prediction of consensus tropical cyclone track forecast error. Mon. Wea. Rev., 135, 1985-1993.

Kaplan, J., M. DeMaria, and J. A. Knaff, 2010: A revised tropical cyclone rapid intensification index for the Atlantic and eastern North Pacific basins. Wea. Forecasting, 25, 220-241.

Knabb, R. D., J.-G. Jiing, C. W. Landsea, and W. R. Seguin, 2005: The Joint Hurricane Testbed (JHT):
Progress and Future Plans. Preprints, Ninth Symp. on Integrated Observing and Assimilation Systems for the Atmosphere, Ocean, and Land Surface (IOAS-AOLS), San Diego, CA, Amer. Meteor. Soc., 2.2. [Available online at www.nhc.noaa.gov/jht /jht_ams_sandiego_2005.pdf.]

Knaff, J. A., M. DeMaria, C. R. Sampson, and J. M. Gross, 2003: Statistical 5-day tropical cyclone intensity forecasts derived from climatology and persistence. Wea. Forecasting, 18, 80-92.

Miller, R. J., A. J. Schrader, C. R. Sampson, and T. L. Tsui, 1990: The Automated Tropical Cyclone Forecasting System (ATCF). Wea. Forecasting, 5, 653-660.

NOAA/NHC, 2002: Joint NOAA, Navy, NASA Hurricane Test Bed terms of reference, $12 \mathrm{pp}$. [Available online at www.nhc.noaa.gov/jht/JHTTOR.13Sep2002 .pdf.]

NOAA/OAR, 2010: Announcement of federal funding opportunity. Executive Summary, 20 pp. [Available online at www.nhc.noaa.gov/jht/JHT_FY11_Full_ Announcement.pdf.]

Pielke, R. A., Jr., J. Gratz, C. W. Landsea, D. Collins, M. A. Saunders, and R. Muslin, 2008: Normalized hurricane damage in the United States: 1900-2005. Nat. Hazards Rev., 9, 29-42.

Rappaport, E. N., and Coauthors, 2009: Advances and challenges at the National Hurricane Center. Wea. Forecasting, 24, 395-419.

Surgi, N., and Coauthors, 2010: Improving operational hurricane prediction with NCEP's Hurricane Weather and Research Forecast (HWRF) system: Future advancements, community involvement and transition of research to operations through the Development Testbed Center (DTC). Preprints, 29th Conf. on Hurricanes and Tropical Meteorology, Tucson, AZ, Amer. Meteor. Soc., 12C.1. [Available on line at http://ams .confex.com/ams/29Hurricanes /techprogram/paper_168642. htm.]

Zhang, F., Y. Weng, J. F. Gamache, and F. D. Marks, 2011: Performance of convection-permitting hurricane initialization and prediction during 2008-2010 with ensemble data assimilation of inner-core airborne Doppler radar observations. J. Geophys. Res. Lett., 38, L15810, doi:10.1029/2011GL048469. 